\title{
The Healthcare Organization in COVID-19 Age: An Evaluation Framework for the Performance of a Telemonitoring Model
}

\author{
Fiorella Pia Salvatore ${ }^{1, *(\mathbb{D})}$ and Simone Fanelli ${ }^{2}$ (D) \\ 1 Department of Economics, University of Foggia, 71121 Foggia, Italy \\ 2 Department of Economics and Management, University of Parma, 43121 Parma, Italy; simone.fanelli@unipr.it \\ * Correspondence: fiorellapia.salvatore@unifg.it
}

check for updates

Citation: Salvatore, F.P.; Fanelli, S. The Healthcare Organization in COVID-19 Age: An Evaluation Framework for the Performance of a Telemonitoring Model. Sustainability 2021, 13, 12765. https://doi.org/ $10.3390 /$ su132212765

Academic Editor: Emidia Vagnoni

Received: 11 October 2021

Accepted: 16 November 2021

Published: 18 November 2021

Publisher's Note: MDPI stays neutral with regard to jurisdictional claims in published maps and institutional affiliations.

Copyright: (C) 2021 by the authors Licensee MDPI, Basel, Switzerland. This article is an open access article distributed under the terms and conditions of the Creative Commons Attribution (CC BY) license (https:/ / creativecommons.org/licenses/by/ $4.0 /)$.

\begin{abstract}
Telemedicine services (TS) are not only supportive for healthcare professionals, but managers also see them as essential for the provision of an efficient, effective, and sustainable healthcare service. Several systems make TS available in different ways and contexts. However, no commonly accepted framework meets the need to draw conclusions about which TS can efficiently be measured. For this purpose, a framework is proposed in order to define a dynamic method of performance evaluation that can be used to improve the sustainable management of a telemonitoring model for COVID-19 patients. A case study analysis based on the experience of three telemedicine networks in different locations providing telemonitoring services (northern, central, and southern Italy) was performed. A total of four phases (1. Identification of the target population; 2. Identification of health needs; 3 . Definition of the operational plan; and 4 . Monitoring of the service by indicators), and seven indicators have been identified. Despite the differences raised in the Italian contexts, applying a performance evaluation framework could help the managerial sector to understand if the service is working as intended and what effects the service is producing on the healthcare organization. Considering the long-term field experience, this framework is an easy-to-use tool that will allow healthcare organizations to evaluate the performance of their telemonitoring model, and improve it according to new needs. Providing a healthcare service in an efficient context is fundamental for the sustainability of the health system as a whole.
\end{abstract}

Keywords: healthcare organization; healthcare management; performance evaluation; telemedicine; telemonitoring

\section{Introduction}

The world is rapidly changing. Information and communication technologies (ICTs) are revolutionizing the way people communicate, explore, and exchange information, while also helping to address current global health problems [1,2]. The ICTs' contribution to telemedicine systems and the development of these systems is primarily concerned with effective change management within a quickly evolving healthcare context $[1,3]$.

Telemedicine literally means "healing at a distance" [4]. In other words, it indicates employing ICT in healthcare organizations to improve patient clinical outcomes by increasing and simplifying both access to care and clinical information. Even currently, in the literature there is no exact definition of telemedicine [5,6]. In the study of Sood [7], 104 peer-reviewed definitions of the telemedicine were identified. However, referring to a most widespread definition elaborated on by the World Health Organization, the following description can be identified:

"The delivery of healthcare services, where distance is a critical factor, by all health care professionals using information and communication technologies for the exchange of valid information for diagnosis, treatment and prevention of disease and injuries, research and evaluation, and for the continuing education of health care providers, all in the interests of advancing the health of individuals and their communities" [8]. 
Considering the many definitions, telemedicine can therefore be recognized as a dynamic and constantly developing science that includes innovations in technology and addresses all the challenges arising from the rapid evolution of the healthcare context $[9,10]$.

ICTs, through their rapid growth and availability in the healthcare sector, have created new potentialities for healthcare services and supply. Indeed, the substitution of traditional types of communication with ICTs methods has inspired the broad interest of healthcare managers aiming at their greater application in the healthcare sector, in order to actualize new, capable, and well-organized ways to provide healthcare services [11,12]. The constant use and worldwide diffusion of the Web and ICT have given a strong impetus to the expansion of the telemedicine sector. Applications using the Internet (such as tele-consultation, tele-doctor-visit, and tele-assistance) and multimedia approaches (such as imaging and video diagnostics) have been significantly improved thanks to ICTs. All these advances have generated a rich range of telemedicine application proposals that the managerial sector of healthcare organizations is implementing everywhere [11-14].

The use of telemedicine in a healthcare organization, more than any other healthmanagement tool, provides various benefits: the reduction of diagnostic variability; the absence of information asymmetries between healthcare system operators; the clinicalmanagerial improvement of the patient; and the important improvements made to the provision of healthcare services, specifically improving admission, quality, and efficiency of the healthcare service and the sustainability of systems [11,15-18].

Alongside these managerial benefits, telemedicine also generates benefits at the patient level. The possibility of receiving assistance and care directly at home allows the patient to have a better health experience, to reduce travel costs, and to create a better relationship with health professionals, generating, in turn, benefits in terms of sustainability. It is well known that the use of telemedicine services supports those communities that reside in areas that are difficult to reach (mountain or rural areas with poor healthcare services and personnel) as they have neither spatial nor temporal barriers [11,19]. In the specific case of COVID-19, the opportunities for contagion are also reduced. Telemedicine is, therefore, the challenge in the healthcare sector that many countries are facing today.

Indeed, the disastrous events that have occurred over the past decade have highlighted the need to understand how to manage healthcare organizations in the face of largely unexpected, extreme shocks. In high-income countries, this was launched by the economic crisis, and in low- and middle-income countries, by unforeseen outbreaks of infectious diseases, with tragic consequences [20]. The rapid spread of the COVID-19 since late 2019 has put a strain on healthcare organizations around the world, connecting with other type of crises, such as economic crises [21]. National responses have been significantly different; some countries have been more successful than others in managing and containing disease transmission and deaths. However, the healthcare organizations of many industrialized countries, such as Italy, have found themselves fighting to face the exponential increase in the number of cases. As for Asian countries, such as India, it was noted that their healthcare organizations already experienced SARS in 2003 and provided a faster and more coordinated response to address and manage the spread of COVID-19. This management mode has led to a more effective containment of the pandemic, at least in the initial shock phase [22]. Lessons learned from the economic crises experienced by these countries have shown that pre-existing weaknesses in the health system can worsen the negative impact on people. This has also been recognized in Greece, where the economic collapse has provided a major transformation of the health system, aimed at addressing some of the major weaknesses identified in the healthcare organizations. In this country, the national response to COVID-19 was led by the National Public Health Organization and the Ministry of Health. The Head of the Public Health Emergency Committee for Infectious Diseases provided daily announcements on the development of the Coronavirus pandemic in Greece in the peak of the pandemic. All Greek healthcare organizations had a clear plan for addressing the constantly evolving challenges of COVID-19. 
Even more than a year after the onset of Coronavirus, healthcare systems management are still working hard to resist the wave of COVID-19 patients due to a staff scarcity, medical devices not always up to the demands, and few intensive care units' beds $[17,18]$. It is precisely in this health emergency that the usefulness of the telemedicine service is found, since digital infrastructures are not compromised and physicians can keep in touch with patients $[9,16]$. Furthermore, the management of telemedicine services is working to ensure that the use of this system is seen as a crucial resource to develop patient supervision, control the spread of the disease, facilitate early and timely identification and management of infected people, and ensure constant care for at risk patients [19,23-25].

Telemedicine is also emerging as a sustainable way to support capacity building of healthcare services in developing countries. It is evident that all the investments made in telemedicine generate a reduction in the burden of disease while growing the sustainability of the healthcare system as a whole [26-29]. Indeed, the constant use of the new technologies has facilitated the dematerialization of some services provided by healthcare organizations, such as patient data collection by creating online archives. However, to guarantee the sustainable effectiveness of the integration between telemedicine strategies and actual healthcare systems, a collaborative technique is needed to identify the best practices, evidence-based trials, and to include social factors into the telemedicine services supply [29-31]. Such a cooperation is strongly related to the skills that the local authorities have, and indeed, the more the local skills are developed, the more programs for the use of telemedicine are effectively implemented in the territory; the relationship can be seen as a spiral whose elements influence each other, increasing the reliability and sustainability of the system $[32,33]$.

Considering the above, it can be seen that the managerial sector of telemedicine applications has reached various levels of success. Although it is widespread in the logic of healthcare organizations that telemedicine should be constantly adopted in the health system to provide routine services [32], particularly during the current period of health emergency, there are several challenges facing the management sector. Included in these challenges is the need for healthcare organizations to identify an evaluation framework for the telemonitoring model adopted for COVID-19 patients. Specifically, the main aim of this study is to identify a series of phases and indicators for the evaluation of performance in healthcare, systematically highlighting the role of telemonitoring services in preventing, diagnosing, treating, and controlling diseases during COVID-19 outbreaks. The findings of the research can make practical and theoretical contributions to the issue of healthcare managerial sustainability. In other words, a framework for the evaluation of a telemonitoring service helps managers to identify management solutions that can contribute to sustainability under three profiles: environmental, social, and economic.

From an environmental point of view, the development of telemedicine and, in particular, of a telemonitoring model, makes it possible to reduce travel and therefore pollution, to limit the emergence of new healthcare facilities, and to reduce medical waste $[33,34]$. From a social point of view, telemedicine allows the patient to live a more comfortable health experience, as he or she can receive assistance and care directly at home, facilitates the function of caregivers, and allows for the creation of a positive relationship between the patient and healthcare professional, increasing overall patient well-being [35,36]. Finally, with regard to economic sustainability, telemedicine allows to generate income, work, and increases performance efficiency. In terms of income, it allows to create new job opportunities for the development and implementation of new technologies in the sector [37]. In terms of performance efficiency, telemedicine allows a more careful resources management and savings for healthcare organization [38-40].

After the analysis of three case studies carried out in healthcare contexts (in northern, central, and southern Italy), a framework of indicators useful for evaluating a model for the telemonitoring of COVID-19 patients will be defined.

The content is structured as follows: after the introduction, the case study method applied to real contexts has been discussed. The third paragraph presents the case studies 
investigated and the performance evaluation framework for the telemonitoring services adopted for COVID-19 patients. Section 4 discusses the applications, strengths, and weaknesses of the proposed framework and provides some conclusions and recommendations to the healthcare managers for applying the framework in healthcare settings.

\section{Materials and Methods}

A qualitative case study approach has been chosen as it uses different types of data, supporting the examination of a phenomenon in an identified context by exploring from different viewpoints the multiple facets of the event [41,42]. The case study approach is principally functional when it is necessary to produce an in-depth investigation of a question, event, or fact in its ordinary context, taking into account that the surrounding context will influence it [43]. Based on the authors' experiences of conducting a series of case studies, some reflections on using this approach, discussion on the crucial steps performed, and the challenges in achieving an in-depth understanding of a practical case in this research have been shown.

In line with several papers published in the literature on this topic, the theory value in supporting the design, selection, conduct, and interpretation of case studies has been recognized [44]. In this way, in order to provide a clear picture of how the telemonitoring services were implemented throughout the Italian territory during the pandemic period, the following Regions were selected: Lombardy, Tuscany and Campania (they reflect the regulations of northern, central, and southern Italy, respectively).

The choice of these areas was based on four different criteria: (1) each Italian macroarea (north, central, and south) had to be represented by one region; (2) the number of the resident population (the highest density for each region was considered); (3) the availability of complete and accessible local regulation; and (4) the number of positive and hospitalized COVID-19 cases for each region. A documentary analysis on secondary data is carried out.

Through the description and in-depth analysis of the projects, a final performance evaluation framework for the telemonitoring services adopted for COVID-19 patients will be proposed.

\section{Results}

3.1. Telemonitoring Model: The Case Studies

3.1.1. The Benchmark in Northern Italy

On the basis of the decree-law n. 14/2020, which regulated for the provision of extraordinary measures through the strengthening of healthcare organizations and the creation of territorial assistance units for people positive with COVID-19 but not hospitalized, the Lombardy Regional Council with Resolution no. XI/2986-23/03/2020 [44], has greatly accelerated the strengthening process of the territorial healthcare network.

In summary, the Lombardy region has launched the following actions:

1. Special Continuity Care Units, aimed at the home management of patients affected by COVID-19 who do not require hospitalization. These units also respond to the need to provide answers to the population located in the areas where the cases of positivity are greater;

2. Syndromic surveillance during the year 2020, training the Health Protection Agencies (HPAs) to enroll a number of physicians to be able to carry out the surveillance of at least $4 \%$ of the population in each district;

3. "COVID-19 Patient Telemonitoring Service" project performed by the Regional Agency for Innovation and Purchasing. The main aim is to realize the service in the shortest possible time, guaranteeing the adoption of new tools, also of a technological nature, to safeguard the spread of the contagion, and, at the same time, verifying the presence of any solutions, supplies, or both, in the form of a donation or free loan that does not affect the overall costs of the project.

In the current pandemic phase, with a high number of cases and consequently of provisions for social separation and home self-isolation, it was necessary to pay particular 
attention to the detection of the clinical flu picture, which could have been evidence of COVID-19 infection. Therefore, the syndromic surveillance was carried out through the collaboration of General Practitioners (GPs) and Pediatricians, and was increased by recruiting an additional equal number of physicians by the HPAs.

Considering the aforementioned formal acts, it was made clear that the HPAs were responsible for both the supervision of cases with mandatory home isolation, and for updating the list of subjects in fiduciary home isolation and symptomatic subjects without evidence of contact.

Additional healthcare offers have been defined and included in a care path, such as:

- Institution of the Special Continuity Care Units (SCCU). Each SCCU can usually manage 20 home accesses in $12 \mathrm{~h}$, taking into account travel times, geographic and demographic variables, and the reporting and recording commitment of the activities carried out.

- Institution of COVID-19 District Areas. These areas are intended for COVID-19 positive patients who would require low intensity observation and assistance. From an organizational point of view, these areas guarantee the presence of nursing, sociohealth, and medical staff (consultancy of geriatric, infectious, and pneumological specialists) and telephone availability 7 days a week, $12 \mathrm{~h}$ a day.

- Institution of palliative care support. This is provided in two different ways: (1) Home care, through the reshaping of the offer for patients with palliative care needs, in order to take care of complex, chronic and fragile COVID-19 patients who have been discharged from healthcare organizations. (2) Consultancy, provision of services by telephone and remote consultation, from the accredited structures for palliative care (Hospice and Home Palliative Care Units).

In light of the abovementioned organizational structure, the Lombard service of COVID-19 patients telemonitoring aims to allow GPs and physicians of healthcare organizations to reduce the number of contacts with high-risk patients, reducing, thus, the possibility of coming into contact with the virus and aggravating the infection spread. The service also responds not only to COVID-19 positive patients, but also to those not yet tested but who have flu symptoms attributable to COVID-19. The system could then be progressively extended to chronic and fragile patients who could, in the contagion event, aggravate their health condition to the point of making it life-threatening. For these patients, there is a need for greater access to the healthcare service, but it is necessary to protect them from exposure to physical contact in a place that, still at the moment, is at high risk.

\subsubsection{The Benchmark in Central Italy}

Based on the Resolution of the Council of Ministers on 31 January 2020, the Tuscany region, with the local Resolution No. 273/2020 [45], strengthened the Regional Integrated Health and Social Plan 2018-2020. Developing this plan was necessary, as new managerial organizational testing was launched in response to the significant increase in the care demand linked to the continuation of the COVID-19 emergency health situation. The managerial sector of healthcare organizations has also deemed it essential to gradually restore ordinary activities by basing the hospital network on the Hub and Spoke model, keeping, as much as possible, all its functions and flexibility for rapid conversion. The legislative measures of the Tuscany region have marked extensive managerial and organizational changes in the healthcare sector, have supported the implementation of a telemonitoring model centered on the fight against the COVID-19 pandemic, and have launched a business investment plan to adequately support the necessary healthcare changes. The actions implemented have concerned the hospital networks, but, having reached the peak of infections, they have also deeply applied to the regional territory.

The telemonitoring project launched in Tuscany aimed at better organizing territorial care, on the one hand, by enhancing the pre-existing territorial organizational solutions such as SCCU, Family and Community Nurses, and Territory Hospital Rapid Intervention 
Groups, and on the other hand, by innovating the structures through the introduction of new organizational models, such as a 24-h nursing guard, specialist consultations in the territories, a territorial mobile group, and an organizational platform that sees the system control room in the company health service center integrated territorially.

The conception of new integrated healthcare organizational models combined with the IT and organizational support platform (telemedicine, teleconsultation, telemonitoring, and single data repository) produces system synergies and has strengthened not only the healthcare territorial governance, but also improved the response to the health needs of citizens, and has guaranteed widespread and correct information to the stakeholders.

In light of the aforementioned organizational structure, the Tuscan telemonitoring model for COVID-19 patients intends to develop a service center dedicated to scheduling the agendas of specialists, planning the interventions to be carried out in the SCCU, carrying out the role of the telemedicine data collection center, coordinating the territorial mobile network, providing the service of the 24-h Operations Center and Nursing On-call service 24-h. Furthermore, the Tuscany region intends to strengthen the operational unit for the continuity of territorial nursing assistance, because it is a structure that responds to the care needs of citizens who require a rapid, targeted, and competent response. This response is processed through coordination and connection with the operating nodes of the network. The logic of managerial functioning provides for maximum integration, not only between hospitals and care local structures, but also between the skills of managers, health professionals, and the healthcare organization as a whole.

\subsubsection{The Benchmark in Southern Italy}

In accordance with the Ministerial Regulations, the Campania region, which had the local Resolution no. 475 on the 3 November 2020 [46], has defined the territorial management path of COVID-19 cases and contacts.

In the context of strengthening the territorial management of COVID-19 patients, primary care plays a decisive role. To strengthen, therefore, the role of primary care, the Campania region has approved some agreements with the departments of general medicine and pediatrics, in order to define the implementation methods of the provisions of the National Collective Agreements relating to the detection of COVID-19 through rapid antigenic swabs.

In summary, the actions launched by the Campania region are:

1. Developing local activities involving the outpatient specialist in an increasingly active way, as a fundamental player in the management of chronicity.

2. Developing the role of pharmacies as being an integral part of the Regional Health Service, and in doing so, they can offer proactive screening and surveillance services from a capillarity perspective. To this end, on 1 December 2020, an agreement was signed for the carrying out of screening tests for SARS-CoV-2 infection by the Campania region pharmacies.

3. Developing the telemonitoring service for COVID-19 patients. The region has financed the development of an existing software in order to integrate an IT platform with useful sections to track the patient's entire path from the beginning of isolation, to the swabs' request, to its execution, and, finally, to the laboratory result, monitoring any possible anomaly.

The Campania regional legislation requires that the telemonitoring service, used for all COVID-19 positive patients, takes place by supplying the user's home with two devices. The first is represented by adhesive patches containing sensors for detecting heart rate, respiratory rate, and for recording an electrocardiogram. The second device is an oximeter. The signals are transmitted to a smartphone, which sends them to the patient data management platform hosted by the healthcare organization. Connected alarms are a crucial tool for managing some critical care issues. For each patient, the system provides for the assignment of a specialist in order to monitor the clinical status and modify, if necessary, the patient's care setting by arranging for a transfer to another healthcare facility. The 
telemonitoring service is also available for SCCU, and, being a certified medical device, the specialist can also prescribe therapies in agreement with the primary care physician.

Finally, the Campania region states that in order for the telemonitoring service to be carried out at the patients' homes, the following conditions should be met: (1) The healthcare target must be connected to the need for home health surveillance in the context of the Coronavirus emergency according to specific access, control, and discharge protocols. (2) The care target must be linked to a condition of chronic pathology with non-selfsufficiency and clinical instability, also taking into account the conditions of social isolation established by the competent authorities.

\subsection{Lessons from the Case Studies: A Framework for Performance Evaluation}

In light of the case studies analyzed, four phases should be followed to implement and evaluate the performance of a telemonitoring model in a healthcare organization:

1. Identification of the target population. This first phase aims to identify all the population that meets certain inclusion criteria for the care service and, in particular, the portion of residents located in territories with exceptional access difficulties (in areas located at a greater distance $60 \mathrm{~min}$ from the nearest health organizations).

2. Identification of health needs. Once the target population in the previous step has been identified, each patient is assigned a risk profile. This is classified according to a Likert scale: very high, high, moderate, and low. Subsequently, on the basis of the geolocation of the patients, it is possible to identify the healthcare organizations which, in order to carry out the telemonitoring service, should possess certain characteristics: a telemedicine clinic; functional organizational path related to taking charge of the patient; and identification of the specialist to whom the diagnostic data should be sent.

3. Definition of the operational plan. The main purpose of the plan is to define the activities to be carried out for the implementation and evaluation of the telemonitoring project, and to detail the roles and functions of all the stakeholders involved in the service management for the healthcare organization. In detail, the macro-activities of the operational plan are:

$\bigcirc \quad$ Identification of managers and health professionals to be involved;

Staff training;

Definition of the actions for the telemonitoring path;

Caregiver training;

Evaluation using process indicators (such as: characteristics of the target population; type of monitoring carried out, including parameters monitored and frequency of monitoring; workflow of the path implemented in the healthcare organization) and outcome indicators (such as: total of users who received a telemedicine device; total telemedicine devices provided to the healthcare organization; number of events managed through telemedicine without transfer results and total of patients for whom the telemedicine service was used; and acceptability of users and operators).

4. Monitoring of the service by indicators. The telemonitoring project is aimed, as a priority, at experimenting with an organizational model capable of enhancing the contribution of telemedicine in the area of local health services. In this perspective, the control and monitoring action will focus not so much on clinical efficacy indicators (inadequate due to the limited time duration and the limited number of cases involved), but rather on indicators capable of providing useful information on the performance and the model transferability to other healthcare contexts.

For a correct impact evaluation of the telemonitoring service provision on the healthcare organization, it is important to identify performance indicators that can be adapted to the system [47]. The indicators classified by area are shown below.

1. Size, relating to the volume of services provided; 
2. Time continuity, relating to the duration and stability of the service;

3. Complexity, relating to the organizational complexity of the service;

4. Quality, relating to the standard and performance of the service;

5. Efficiency, relating to the cost of the service;

6. Effectiveness, relating to the comparison with the patients affected by the pathology covered by the telemonitoring service, but followed in the conventional way;

7. Satisfaction, relating to the detection of satisfaction by users.

To specify the usefulness of these indicators in the performance evaluation of the telemonitoring service, and to illustrate what they refer to, in Table 1, more features are shown. 
Table 1. Performance indicators included in the evaluation framework of the telemonitoring model.

\begin{tabular}{|c|c|c|c|c|c|}
\hline Performance Indicators & & Evaluation D & mensions & & Measurement Mode \\
\hline Size & $\begin{array}{c}\text { Target Coverage: } \% \text { of users } \\
\text { followed out of the total number } \\
\text { of users affected by COVID-19 in } \\
\text { the area of interest }\end{array}$ & $\begin{array}{l}\text { Absolute size: Followed } \\
\text { users/12 months }\end{array}$ & $\begin{array}{l}\text { Average size: Average number } \\
\text { of contacts/month }\end{array}$ & $\begin{array}{l}\text { Dynamic aspect: No. of users } \\
\text { affected by COVID-19 followed } \\
\text { in the last } 12 \text { months/No. of } \\
\text { users affected by COVID-19 } \\
\text { followed in the previous } \\
12 \text { months }\end{array}$ & Objective indicator \\
\hline Time continuity & $\begin{array}{l}\text { Duration: No. of months from the } \\
\text { activation of the service }\end{array}$ & $\begin{array}{l}\text { Stability: Dispersion indices } \\
\text { (e.g., standard deviation and } \\
\text { range of variation) of the } \\
\text { average size indicator for a } \\
\text { reference time period }\end{array}$ & & & Objective indicator \\
\hline Complexity & $\begin{array}{l}\text { Qualitative aspect: Type of } \\
\text { professional figures involved in } \\
\text { the provision of the service } \\
\text { (GP } 1 \text {, Medical Specialist, and } \\
\text { Nurse, etc.) }\end{array}$ & $\begin{array}{l}\text { Quantitative aspect: No. of } \\
\text { operators involved in the } \\
\text { provision of the service (person } \\
\text { months)/No. of users }\end{array}$ & & & $\begin{array}{c}\text { Subjective indicator } \\
\text { (quali-quantitative } \\
\text { attributes) }\end{array}$ \\
\hline Quality & $\begin{array}{l}\text { Standard of service: Standard } \\
\text { response time }\end{array}$ & $\begin{array}{l}\text { Response performance: } \\
\text { No. of performances within } \\
\text { standard time }\end{array}$ & $\begin{array}{l}\text { Response time of the COVID-19 } \\
\text { Operations Center: Reporting } \\
\text { time for alerts from the } \\
\text { dashboard of the } \\
\text { telemonitoring platform } \\
\text { to the GP, } \\
\text { or to the Specialist, or to the } \\
\text { Emergency Department }\end{array}$ & & Objective indicator \\
\hline Efficiency & $\begin{array}{l}\text { Service functionality: Total annual } \\
\text { cost of maintaining the service } \\
\text { (personnel, equipment, and } \\
\text { management, etc.)/No. of users } \\
\text { affected by COVID-19 followed }\end{array}$ & & & & Objective indicator \\
\hline
\end{tabular}


Table 1. Cont.

Performance Indicators

Reduction in the days of hospitalization: No. of

hospitalization days in the last 12 months per user affected by COVID-19 followed by

Effectiveness telemonitoring $/ \%$ of days of hospitalization in the last

12 months per user affected by COVID-19 followed in conventional mode

Qualitative aspect: Questionnaire administered to users (patients and caregivers)
Reduction in the incidence of

Reduction in the time spent by re-hospitalizations among users: patients in EUD ${ }^{2}$ : Time (hours) \% of re-hospitalizations in the spent in the last 12 months in last 12 months among users EUD per user affected by affected by COVID-19 COVID-19 followed by

telemonitoring/Time (hours) spent in EUD in the last

12 months per user affected by COVID-19 followed in conventional mode

Absolute quantitative aspect:

No. of users who leave the telemonitoring path by choice/12 months (drop-out) affected by COVID-1
followed by

elemonitoring $/ \%$ of re-hospitalizations in the last 12 months among users affected by COVID-19$$
\text { followed in }
$$

conventional mode

Relative quantitative aspect:

No. of users who leave the

telemonitoring path by

hoice/12 months/number of

COVID-19 users followed

(drop-out)
Reduction of inappropriate

COVID-19 user access to the

EUD: No. of users affected by

COVID-19 accessing to the EUD followed in

telemonitoring/No. of users affected by COVID-19

accessing the EUD followed in conventional mode
Subjective indicator quali-quantitative at-tributes)

Subjective indicator (quali-quantitative attributes)

GP: General Practitioner. ${ }^{2}$ EUD: Emergency and Urgency Department. 


\section{Discussion and Conclusions}

Due to the ever-increasing number of elderly people and chronic diseases, reorganizing local healthcare is a necessity [16,48]. The adoption of innovative care models that facilitates access to care, moving it from the hospital to the territory, while ensuring responses to new health needs that are effective from an organizational point of view and efficient in terms of sustainability, represents a great need for the managerial sector of healthcare organizations $[13,18,29,48]$. In this path that can no longer be postponed, the telemedicine tool, and, in particular, telemonitoring, can be decisive and represents the results of continuous technological innovation, recognized internationally for the relevance and for the positive impact it can have on health.

The results obtained in this study, as well as the definition of the performance evaluation framework for the telemonitoring model adopted for COVID-19 patients, provide practical implications for the healthcare sector. Telemonitoring models present themselves as a powerful vehicle for innovation in the healthcare context [11,47]. If, on the one hand, they influence the resources management of a healthcare organization, since they allow the circulation of healthcare professionals and managers in the different districts in a more rational and sustainable way, and reduce the social cost of pathologies [29,48], on the other, these models influence the quality of care, because they facilitate the continuity of information between healthcare professionals, while enhancing patient self-management $[19,25,40]$.

The advantages for the National Health Service of the new organizational models based on telemedicine can be identified: in the "real-time" interventions of emergencies, in the protected hospital discharge, in the reduction of hospitalizations of the chronically ill, in the reduced recourse to hospitalizations in nursing homes and the rest of the elderly, in reducing health "commuting" both at regional and national level, and, finally, in the best living conditions that can be guaranteed to subjects at risk, ensuring them greater safety and autonomy $[13,17,28,48]$. Furthermore, some critical aspects can also be detected among the structural aspects of the health service. The weakness, in general, in conceiving oneself as an "integrated system" and the weakness of the governance principles of the healthcare organization, from which the self-referential tendencies that invalidate the organizational models arise, represent a serious and dangerous damage, which negatively affects the effectiveness, the efficiency, and the sustainability of the service provided by healthcare organizations [28,30,49].

At a time when the debate on the need to profoundly review the managerial and organizational structure of the healthcare system has been revived $[30,31,50]$, some of the following aspects need to be considered:

- "Take care of" the systems that "cure": the organizational system, seen as a "complex social system", requires a profound reorganization related to the supporting paradigms ("system vision", improvement of the managerial sector contribution, and multi-competent strategic planning);

- Innovate healthcare practices to pursue efficient system results through the development of integrated Clinical Governance programs. This implies a rethinking of the concepts of strategic planning, clinical methodology, systemic method of construction of Diagnostic Therapeutic and Care Pathways (DTCP), revision of the skills and responsibilities of managers, and of the "operational mechanisms" of the healthcare organization (such as the development of synergies between information systems, planning and control, and evaluation of company performance);

- Develop culture and practices (management by objectives). Business productivity should not be seen as the only "core" element. It is necessary to highlight the individual contributions through DTCP integrated with telemedicine tools and built on the "products-results" method;

- Streamline, through retraining, care processes aiming at innovative processes, based on remote assistance and telemonitoring. 
The present study is not without limitations. Given the numerous regulations that the regions have enacted to manage the COVID-19 pandemic, it is assumed that those mentioned in this study may have been integrated or modified based on the evolution of the pandemic in progress, or a combination thereof. Consequently, the case studies shown should be considered as "pictures" of a given moment, dating back to the publication dates of the regional regulations. In addition, the phases identified to implement, manage, and evaluate a telemonitoring project within a healthcare organization were the outcomes resulting from the analysis of the case studies. Considering that three case studies demonstrating Italian territorial differences (north, central, and south) have been investigated, it is believed that the generalization of the results may be difficult. However, the ability to provide a follow-up and keep the framework proposed in this study updated, will make it possible to provide recommendations on the implementation of this performance evaluation model in other healthcare settings as well.

In conclusion, the entire flow of health and socio-health activities should be rethought from an overall strategic perspective to ensure consistency in the quality of care, its appropriateness and efficiency. The factors that must contribute to this realization are multiple, multidisciplinary, and strictly dependent on each other. In light of the results, it is necessary to implement new interconnected organizational, technological, communication, and managerial models that provide for high professional and governance standards $[32,51,52]$. The digitalization of the healthcare sector and the application of tools that allow to evaluate in a sustainable way the performance obtained by new telemonitoring services provided to COVID-19 patients, can make an important contribution both to the optimization of healthcare processes, and to the restructuring of healthcare organizations [29,30]. Despite the evidence emerging from this study, it is necessary to develop further research to confirm the results and to define the conditions useful for an increasingly effective implementation of telemedicine services. For example, the framework proposed in this study is limited to COVID-19 and the Italian context, thus it would be useful for future research to test it for other diseases, or in other countries.

The current health emergency, the need to implement and integrate telemedicine services in the National Health Systems, and the need to adopt efficient managerial tools for evaluating performance, represent global challenges that must lay the foundations for change and, therefore, for the structural improvement of the healthcare organization as a whole.

Author Contributions: Conceptualization, F.P.S. and S.F.; methodology, F.P.S.; validation, F.P.S. and S.F.; formal analysis, F.P.S.; investigation, F.P.S.; resources, F.P.S. and S.F.; data curation, F.P.S.; writingoriginal draft preparation, F.P.S.; writing - review and editing, F.P.S. and S.F.; supervision, F.P.S.; project administration, F.P.S. and S.F. All authors have read and agreed to the published version of the manuscript.

Funding: This research received no external funding.

Institutional Review Board Statement: Not applicable.

Informed Consent Statement: Not applicable.

Data Availability Statement: Not applicable.

Conflicts of Interest: The authors declare no conflict of interest.

\section{References}

1. Honka, A.; Kaipainen, K.; Hietala, H.; Saranummi, N. Rethinking health: ICT-enabled services to empower people to manage their health. IEEE Rev. Biomed. Eng. 2011, 4, 119-139. [CrossRef]

2. Fares, N.; Sherratt, R.S.; Elhajj, I.H. Directing and Orienting ICT Healthcare Solutions to Address the Needs of the Aging Population. Healthcare 2021, 9, 147. [CrossRef] [PubMed]

3. Akhtar, R.; Alam, S.; Siddiquee, N.K. Telemedicine: An ICT based healthcare approach to ensure health service for all. Int. J. Community Med. Public Health 2019, 6, 3732. [CrossRef] 
4. Strehle, E.M.; Shabde, N. One hundred years of telemedicine: Does this new technology have a place in paediatrics? Arch. Dis. Child. 2006, 91, 956-959. [CrossRef] [PubMed]

5. Roh, C.Y. Telemedicine: What it is, where it came from, and where it will go. Comp. Technol. Transf. Soc. 2008, 6, 35-55. [CrossRef]

6. $\quad$ Rose, H. Telemedicine: What is it? Point Vétérinaire 2018, 49, 34-37.

7. Sood, S.P.; Negash, S.; Mbarika, V.W.; Kifle, M.; Prakash, N. Differences in public and private sector adoption of telemedicine: Indian case study for sectoral adoption. Stud. Health Technol. Inform. 2007, 130, 257-268.

8. WHO. A Health Telematics Policy in Support of WHO's Health-for-All Strategy for Global Health Development: Report of the Who Group Consultation on Health Telematics; World Health Organization: Geneva, Switzerland, 1998.

9. Talal, A.H.; Sofikitou, E.M.; Jaanimägi, U.; Zeremski, M.; Tobin, J.N.; Markatou, M. A framework for patient-centered telemedicine: Application and lessons learned from vulnerable populations. J. Biomed. Inform. 2020, 112, 103622. [CrossRef]

10. Pilosof, N.P.; Barrett, M.; Oborn, E.; Barkai, G.; Pessach, I.M.; Zimlichman, E. Telemedicine implementation in COVID-19 ICU: Balancing physical and virtual forms of visibility. HERD Health Environ. Res. Des. J. 2021, 14, 34-48. [CrossRef]

11. Craig, J.; Patterson, V. Introduction to the practice of telemedicine. J. Telemed. Telecare 2005, 11, 3-9. [CrossRef] [PubMed]

12. Currell, R.C.; Urquhart, P.; Wainwright, R.L. Telemedicine versus face to face patient care: Effects on professional practice and health care outcomes. Cochrane Database Syst. Rev. 2000, 2, CD002098.

13. Lombrano, A.; Iacuzzi, S. Comparing health system performance. Econ. Aziend. Online 2020, 11, 175-189.

14. Alvandi, M. Telemedicine and its role in revolutionizing healthcare delivery. Am. J. Acc. Care 2017, 5, e1-e5.

15. Heinzelmann, P.J.; Lugn, N.E.; Kvedar, J.C. Telemedicine in the future. J. Telemed. Telecare 2005, 11, 384-390. [CrossRef] [PubMed]

16. Salvatore, F.P.; Fanelli, S. Patient-related complexity of care in healthcare organizations: A management and evaluation model. Int. J. Environ. Res. Public Health 2020, 17, 3463. [CrossRef]

17. Alami, H.; Lehoux, P.; Fleet, R.; Fortin, J.P.; Liu, J.; Attieh, R.; Ag Ahmed, M.A. How can health systems better prepare for the next pandemic? Lessons learned from the management of COVID-19 in Quebec (Canada). Front. Public Health 2021, 9, 696.

18. Leoni, G.; Lai, A.; Stacchezzini, R.; Steccolini, I.; Brammer, S.; Linnenluecke, M.; Demirag, I. Accounting, management and accountability in times of crisis: Lessons from the COVID-19 pandemic. Account. Audit. Account. J. 2021, 34, 1305-1319. [CrossRef]

19. Hollander, J.E.; Carr, B.G. Virtually perfect? Telemedicine for COVID-19. N. Engl. J. Med. 2020, 382, 1679-1681. [CrossRef]

20. Barasa, E.; Mbau, R.; Gilson, L. What is resilience and how can it be nurtured? A systematic review of empirical literature on organizational resilience. Int. J. Health Policy Manag. 2018, 7, 491-503.

21. Bozorgmehr, K.; Saint, K.; Kaasch, A.; Stuckler, D.; Kentikelenis, A. COVID and the convergence of three crises in Europe. Lancet Public Health 2020, 5, e247-e248. [CrossRef]

22. Legido-Quigley, H.; Asgari, N.; Teo, Y.Y.; Leung, G.M.; Oshitani, H.; Fukuda, K.; Cook, A.R.; Hsu, L.Y.; Shibuya, K.; Heymann, D. Are high-performing health systems resilient against the COVID-19 epidemic? Lancet 2020, 395, 848-850. [CrossRef]

23. Kaundinya, T.; Agrawal, R. Unpacking a Telemedical Takeover: Recommendations for Improving the Sustainability and Usage of Telemedicine Post-COVID-19. Qual. Manag. Health Care 2021. [CrossRef] [PubMed]

24. Jennett, P.A.; Hall, L.A.; Hailey, D.; Ohinmaa, A.; Anderson, C.; Thomas, R.; Lorenzetti, D.; Scott, R.E. The socio-economic impact of telehealth: A systematic review. J. Telemed. Telecare 2003, 9, 311-320. [CrossRef] [PubMed]

25. Mafrolla, E.; D'Amico, E. Patients' mobility as an indicator for (in) efficiency: A panel data analysis on Italian health care authorities. Health Econ. Rev. 2013, 3, 1-13. [CrossRef] [PubMed]

26. ISS. COVID-19 Integrated Surveillance: Key National Data. 2020. Available online: www.epicentro.iss.it/en/coronavirus/sarscov-2-integrated-surveillance-data (accessed on 1 October 2021).

27. ISS. Characteristics of COVID-19 Patients Dying in Italy. 2020. Available online: www.epicentro.iss.it/coronavirus/bollettino/ Report-COVID-2019_26_marzo_eng.pdf (accessed on 1 October 2021).

28. AlJaberi, O.A.; Hussain, M.; Drake, P.R. A framework for measuring sustainability in healthcare systems. Int. J. Healthc. Manag. 2020, 13, 276-285. [CrossRef]

29. Cavicchi, C.; Oppi, C.; Vagnoni, E. On the feasibility of integrated reporting in healthcare: A context analysis starting from a management commentary. J. Manag. Gov. 2019, 23, 345-371. [CrossRef]

30. Faggini, M.; Cosimato, S.; Nota, F.D.; Nota, G. Pursuing Sustainability for Healthcare through Digital Platforms. Sustainability 2019, 11, 165. [CrossRef]

31. Polese, F.; Carrubbo, L.; Caputo, F.; Sarno, D. Managing healthcare service ecosystems: Abstracting a sustainability-based view from hospitalization at home $(\mathrm{HaH})$ practices. Sustainability 2018, 10, 3951. [CrossRef]

32. Lai, A.; Stacchezzini, R. Organisational and professional challenges amid the evolution of sustainability reporting: A theoretical framework and an agenda for future research. Meditari Account. Res. 2021, 29, 405-429. [CrossRef]

33. Dullet, N.W.; Geraghty, E.M.; Kaufman, T.; Kissee, J.L.; King, J.; Dharmar, M.; Smith, A.C.; Marcin, J.P. Impact of a university-based outpatient telemedicine program on time savings, travel costs, and environmental pollutants. Value Health 2017, 20, 542-546. [CrossRef]

34. Vidal-Alaball, J.; Franch-Parella, J.; Lopez Seguí, F.; Garcia Cuyàs, F.; Mendioroz Peña, J. Impact of a Telemedicine Program on the Reduction in the Emission of Atmospheric Pollutants and Journeys by Road. Int. J. Environ. Res. Public Health 2019, 16, 4366. [CrossRef] [PubMed] 
35. Shea, S.; Kothari, D.; Teresi, J.A.; Kong, J.; Eimicke, J.P.; Lantigua, R.A.; Weinstock, R.S. Social impact analysis of the effects of a telemedicine intervention to improve diabetes outcomes in an ethnically diverse, medically underserved population: Findings from the IDEATel Study. Am. J. Public Health 2013, 103, 1888-1894. [CrossRef]

36. Boaz, M.; Hellman, K.; Wainstein, J. An automated telemedicine system improves patient-reported well-being. Diabetes Technol. Ther. 2009, 11, 181-186. [CrossRef]

37. Pandian, P.S. An overview of telemedicine technologies for healthcare applications. Int. J. Biomed. Clin. Eng. (IJBCE) 2016, 5, 29-52. [CrossRef]

38. Russo, J.E.; McCool, R.R.; Davies, L. VA telemedicine: An analysis of cost and time savings. Telemed. E-Health 2016, 22, 209-215. [CrossRef] [PubMed]

39. Salvioni, D.; Gennari, F. Corporate governance, ownership and sustainability. Corp. Ownersh. Control 2016, 13, 606-614. [CrossRef]

40. Zanaboni, P.; Wootton, R. Adoption of routine telemedicine in Norwegian hospitals: Progress over 5 years. BMC Health Serv. Res. 2016, 16, 496. [CrossRef] [PubMed]

41. Baxter, P.; Jack, S. Qualitative case study methodology: Study design and implementation for novice researchers. Qual. Rep. 2008, 13, 544-559. [CrossRef]

42. Yin, R.K. Case Study Research, Design and Method; Sage Publications Ltd.: London, UK, 2009.

43. Rashid, Y.; Rashid, A.; Warraich, M.A.; Sabir, S.S.; Waseem, A. Case study method: A step-by-step guide for business researchers. Int. J. Qual. Methods 2019, 18, 1609406919862424. [CrossRef]

44. Giunta Regionale Lombardia. Determinazioni in Ordine all'Emergenza Epidemiologica da COVID-19-Area Territoriale. Available online: https://www.asst-pavia.it/sites/default/files/documenti/DGR\%202986\%2023.03.2020.pdf (accessed on 2 October 2021).

45. Giunta Regionale Toscana. Piano Sanitario e Sociale Integrato Regionale 2018-2020. Available online: http:/ /www.informareunh it/wp-content/uploads/DGRT_n.1159_del_06-08-2020-VitaIndipendente.pdf (accessed on 4 October 2021).

46. Giunta Regionale Campania. Approvazione Piano di Potenziamento e Riorganizzazione della Rete di Assistenza Territoriale. Available online: http:/ / www.aiopcampania.it/public/normativa/743f6f8d7f4b42b4a23f410082f6255a.pdf (accessed on 4 October 2021).

47. Ministero della Salute. Telemedicina. Linee di Indirizzo Nazionali. Available online: https://www.salute.gov.it/imgs/C_17 _pubblicazioni_2129_allegato.pdf (accessed on 12 September 2021).

48. Cavicchi, C.; Vagnoni, E. Does intellectual capital promote the shift of healthcare organizations towards sustainable development? Evidence from Italy. J. Clean. Prod. 2017, 153, 275-286. [CrossRef]

49. Boyne, J.J.; Vrijhoef, H.J. Implementing telemonitoring in heart failure care: Barriers from the perspectives of patients, healthcare professionals and healthcare organizations. Curr. Heart Fail. Rep. 2013, 10, 254-261. [CrossRef] [PubMed]

50. Adams, C.A.; Muir, S.; Hoque, Z. Measurement of sustainability performance in the public sector. Sustain. Account. Manag. Policy J. 2014, 5, 46-67. [CrossRef]

51. Fanelli, S.; Lanza, G.; Francesconi, A.; Zangrandi, A. Facing the pandemic: The Italian experience from health management experts' perspective. Am. Rev. Public Adm. 2020, 50, 753-761. [CrossRef]

52. Fanelli, S.; Lanza, G.; Enna, C.; Zangrandi, A. Managerial competences in public organisations: The healthcare professionals' perspective. BMC Health Serv. Res. 2020, 20, 303. [CrossRef] [PubMed] 